\title{
Analysis of Neutronics and Thermal-Hydraulic Behavior in a Fuel Pin of Pressurized Water Reactor (PWR)
}

\author{
Md. Ghulam Zakir*, M. A. Rashid Sarkar, Altab Hossain \\ Nuclear Science and Engineering (NSE) Department, Military Institute of Science and Technology (MIST), Dhaka, Bangladesh \\ Email: *paban81@gmail.com
}

How to cite this paper: Zakir, Md.G., Sarkar, M.A.R. and Hossain, A. (2019) Analysis of Neutronics and Thermal-Hydraulic Behavior in a Fuel Pin of Pressurized Water Reactor (PWR). World Journal of Nuclear Science and Technology, 9, 74-83.

https://doi.org/10.4236/wjnst.2019.92005

Received: January 25, 2019

Accepted: April 20, 2019

Published: April 23, 2019

Copyright $\odot 2019$ by author(s) and Scientific Research Publishing Inc. This work is licensed under the Creative Commons Attribution International License (CC BY 4.0).

http://creativecommons.org/licenses/by/4.0/

(c) (i) Open Access

\begin{abstract}
This paper presents a comparative analysis of different parameters such as enthalpy, moderator temperature, moderator density, flow velocity, pressure, and fuel temperature profile at the fuel pin cell level of PWR. Moreover, in this paper pitches to fuel pin radius ratio are varied from 2.3 to 4 . The methods and implementation strategy are such that the coupled neutronic and thermal-hydraulic analysis is executed in a fully one dimensional (1D) manner. The thermal hydraulic is based on moderator/coolant mass and enthalpy equation together with one group diffusion equation for fuel pin. Modelling of fuel pin cell and subchannel is executed in two steps. First, the governing equations are derived assuming that all the parameters appearing in the equations are temperature independent. Fuel pin centerline temperature and radially averaged temperature equations are derived from Fourier laws of thermal conductivity. Finally, diffusion coefficient, fission cross-section and absorbing cross-section are evaluated with respect to the fuel pin temperature. The outcome will be helpful for further neutronics and thermal analysis of PWR. Thermal hydraulics parameter varies the maximum 30 percentage from the lowermost value.
\end{abstract}

\section{Keywords}

Fuel Pin, Pitch, Sub-Channel, Neutronics and Thermal Hydraulics

\section{Introduction}

The Light Water Reactor (LWR) Nuclear Fuel Development Research and Development $(\mathrm{R} \& \mathrm{D})$ is mainly focused on improving reactor core economics and safety margins through the development of fuel design. To obtain significant economical improvements while remaining safety boundaries, significant steps 
beyond improvements in the current generation of nuclear fuel are required. Primary improvements in the field of fuel pin and pallet design, cladding interaction with coolant, enhanced fuel burn up; fuel composition is highly essential. To achieve massive development within next 20 - 25 years in nuclear industry, advanced fuel design should be introduced by today and those designs must be implemented with confidence [1].

For LWR, strong economic incentives exist with higher fuel consumption by maintaining its reliability. One of the most effective ways to increase fuel consumption and to use fuel pin more efficiently is raising the fuel volume fraction in the core, which in terms of thermal hydraulic and structural design can be done by increasing the fuel pin diameter and by decreasing the fuel pitch. Under certain operating condition, small fuel pitch can cause fuel pin damage or distortion, thus examining in some detail the fuel pin pitch optimization of a large LWR, taking these problems into consideration [2].

\section{Objective}

The aim of this work is to analysis both thermal-hydraulic and neutronic behavior along the channel of the fuel pins. The overall objectives are divided into several steps:

- To vary the fuel pitch to pin radius ratio;

- To investigate thermal hydraulic behavior by analyzing coolant temperature, pressure, density and enthalpy inside fuel assembly.

\section{Methodology}

The entire methodology is performed on three steps. Firstly, neutron flux is calculated from one group diffusion equation. Volumetric heat source is determined from this equation as well.

Thus, other parameters such as temperature of the fluid from fuel cladding are also determined. Finally, an equation of enthalpy is developed from the Gauss theorem and enthalpy conservation equation.

Enthalpy is determined for four different fuel pin pitch to radius ratio. Thus, other parameters such as temperature profile and moderator density profile are determined.

However, several assumptions have been made:

Pressure throughout the reactor is assumed to be constant and it is 15.5 bar. Moreover, no pressure drop will occur in the reactor.

Finally, using above two properties and implementing all values from steam table leads to determine moderator temperature and density. Those two parameters are determined for four distinct fuel pin pitch to radius ratio. Thus, other parameters: diffusion coefficient, macroscopic cross-section, fuel radially averaged temperature, coolant velocity and pressure are also determined by using Matlab.

\section{Model and Equation}

In this work, uranium-235 is used which is $3.957 \%$ enriched. The thermal hy- 
draulics behaviors along the channel of two adjacent fuel pins are properly analyzed. The parameters relevant to the fuel pins are mentioned in Table 1 and Table 2. The pitch between two fuel pins is varied to investigate the change in enthalpy, coolant temperature, coolant velocity. Radius of the pin remained constant. It is assumed that the higher pitch to fuel pin radius ratio reflects more distance between two pins. Thus, more space can be added for coolants between the two fuel pins and the volume for the coolant can be increased as well.

$$
\begin{gathered}
\nabla^{2} \varphi(z)+\frac{\left(v \Sigma_{f}-\Sigma_{a}\right)}{D} \varphi(z)=0 \\
\varphi(z)=C \sin \left(\frac{\pi z}{H}\right)
\end{gathered}
$$

$\varphi$ is defined as neutron flux, $v, \Sigma_{f}, \Sigma_{a}$ are the neutron released per fission, macroscopic fission cross-section, macroscopic absorbing cross-section and $D$ is diffusion coefficient. The solution of Equation (1) is Equation (2). Volumetric heat flux and moderator enthalpy is determined from Equation (2).

$$
\begin{gathered}
q^{\prime \prime}(z)=-\frac{R_{f p}^{2}}{2 R_{c o}} k \Sigma_{f} C \sin \left(\frac{\pi z}{H}\right) \\
\bar{h}(z)=\bar{h}(0)-\frac{P_{w}}{G A} \frac{R_{f p}^{2}}{2 R_{c o}} k \Sigma_{f} C \frac{H}{\pi}\left(\cos \left(\frac{\pi z}{H}\right)-1\right) \\
C=\frac{Q}{2 K \Sigma_{f} H R_{f p}^{2}}
\end{gathered}
$$

$q^{\prime \prime}$ is noted as heat dissipated to fluid from the cladding. $R_{f p}$ is the radius of the fuel pin, $k$ is recoverable energy per fission event, $h$ is the enthalpy, $H$ is the total height of the fuel pin. $R_{c o}$ is defined radius of the pin including the cladding. $z$ defines any parameter value along the $z$ axis or along the vertical axis. $Q$ is power produced by one fuel pin. Enthalpy is defined in Equation (4).

$$
T_{\text {mod }}=\frac{\left(h(z)-h_{0}\right)}{\left(h_{1}-h_{0}\right)} \times\left(T_{1}-T_{0}\right)+T_{0}
$$

$T_{\text {mod }}$ is moderator temperature, $h_{1}$ is the updated enthalpy at the end of node, $h_{0}$ initial enthalpy at the beginning of node, $T_{1}$ temperature at the end of node, $T_{0}$ initial temperature at the beginning of the node. Total height is discretized into 37 nodes. By Equation (6) temperature of the moderator is updated from the moderator enthalpy.

$$
T_{f p}^{\max }=R_{e f f} R_{f}^{2} \pi q^{\prime \prime \prime}+\bar{T}_{\text {mod }}
$$

$T_{f}^{\max }$ is noted as maximum fuel centerline temperature, $R_{e f f}$ is effective thermal resistance, $q^{\prime \prime \prime}$ is volumetric heat flux.

The assumptions are made:

- the system is considered to be at steady-state conditions;

- the fluid contains no volumetric heat source/sink; 
- the coolant is always assumed to remain in single-phase (PWR example);

- the flow is assumed to be mono-dimensional along the vertical $z$-axis;

- the neutron transport will be described by using one-group diffusion theory;

- the thermal conductivity of the fuel is assumed to be temperature-independent;

- the effective thermal resistance is assumed to be constant along the channel;

- the friction factor is assumed to be constant along the channel;

- Fuel pin radius measured including the cladding, however, cladding material has not been taken into account.

Fuel Pin Diameter including cladding is $8 \mathrm{~mm}$.

A nuclear reactor core is the portion of a nuclear reactor containing the nuclear fuel components where the nuclear reactions take place and the heat is generated.

A structured group of fuel pins (long, slender, metal tubes containing pellets of fissionable material, which provide fuel for nuclear reactors). Depending on the design, each reactor vessel may have dozens of fuel assemblies (also known as fuel bundles), each of which may contain 200 or more fuel pins. A long, slender, zirconium metal tube contains pellets of fissionable material, which provide fuel for nuclear reactors. Fuel pins are assembled into bundles called fuel assemblies, which are loaded individually into the reactor core. Table 1 presents fuel pin pitch and pitch to radius ratio which are used to determine different parameters. Moreover, Table 2 presents specific initial conditions and other parameters related to the problem. Figure 1 presents core, fuel assembly and fuel pin with pitch between two adjacent pins. Apart from this, subchannel among four pins and subchannel among three pins are shown in Figure 2. In this paper, subchannel among the four pins is implemented.

Table 1. Fuel pin and pitch design data.

\begin{tabular}{cc}
\hline Pitch $(\mathrm{mm})$ & Pitch to radius ratio \\
\hline 9.2 & 2.3 \\
10.4 & 2.6 \\
11.6 & 2.9 \\
16 & 4.0 \\
\hline
\end{tabular}

Table 2. Problem specification.

$\begin{array}{cc}\text { Parameters } & \text { Data } \\ \text { Axial Height }(\mathrm{m}) & 4.20 \\ \text { Fuel Pin Radius without cladding }(\mathrm{mm}) & 3.5 \\ \text { Power produced by one fuel pin }(\mathrm{W}) & 6.5 \times 10^{4} \\ \text { Recoverable energy per fission event }(\mathrm{J}) & 3.2 \times 10^{-11} \\ \text { Flow velocity at the inlet of the channel }\left(\mathrm{ms}^{-1}\right) & 4.34 \\ \text { Flow temperature at the inlet of the channel }(\mathrm{K}) & 556.51 \\ \text { Macroscopic fission cross-section }\left(\mathrm{cm}^{-1}\right) & 0.028\end{array}$



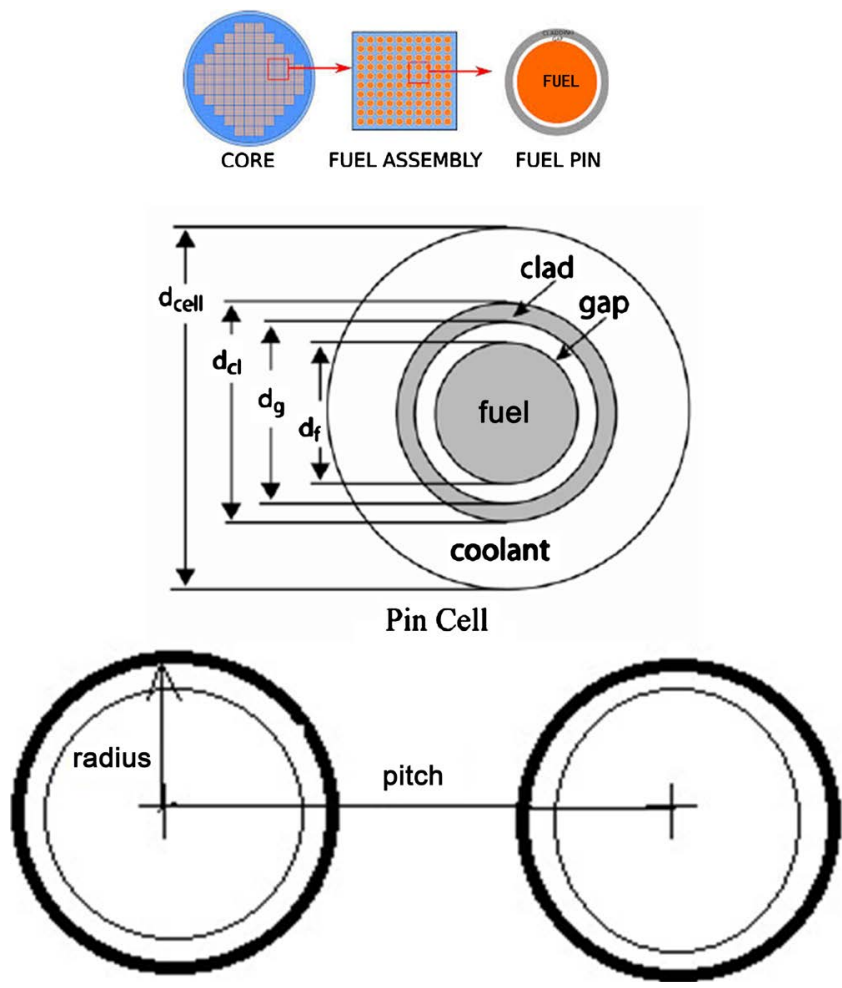

Figure 1. The radius and pitch between two pins.
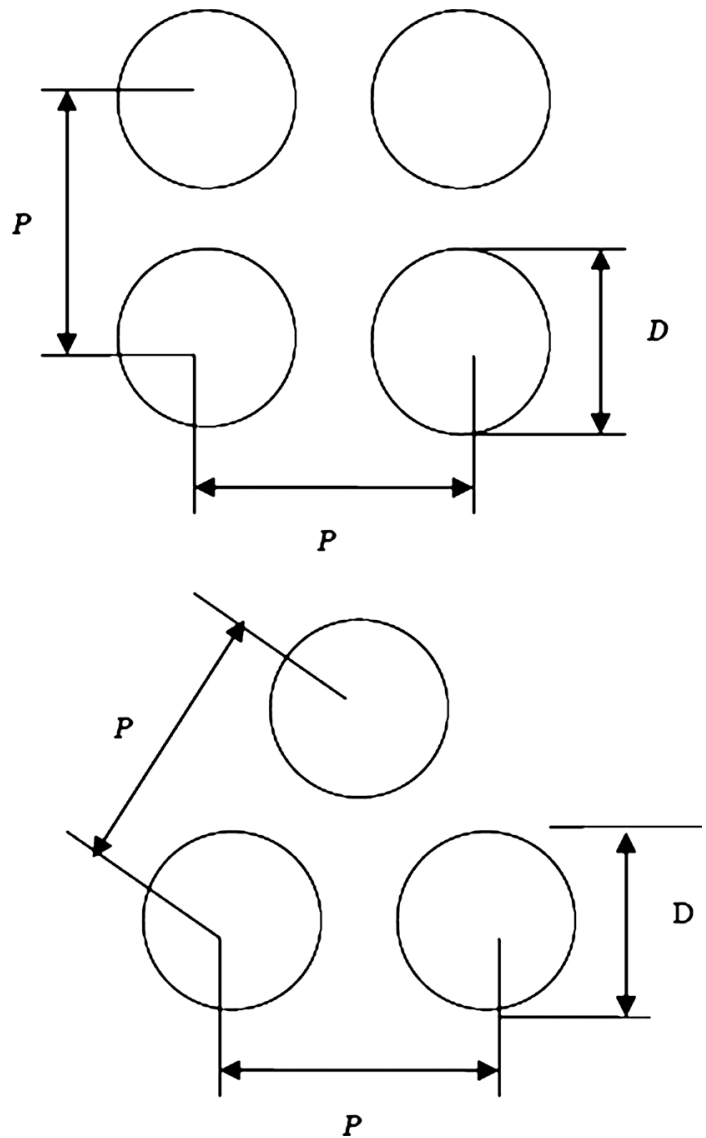

Figure 2. Different design for various fuel assembly. 


\section{Result and Discussions}

It is found in Figure 3 that maximum enthalpy of the coolant is determined for lowest fuel pitch to pin radius ratio and minimum enthalpy is determined for maximum fuel pitch to pin radius ratio. More enhancement of pitch will result in more flatten of the enthalpy curve. However, an optimum range between 2.6 to 2.9 shows better results from both the power generation and safety aspects. Maximum enthalpy for minimum pitch to radius ratio 2.3 is a concern from the safety aspects. On the other hand, less enthalpy to the coolant results in lower power generation. An enthalpy range from $1500 \mathrm{KJ}$ to $1200 \mathrm{KJ}$ is desired value for PWR. As a result, a fuel pitch to radius ratio 2.9 to 4 is desirable for PWR.

Figure 4 shows the change in moderator temperature and moderator density respectively. For steady state condition, inlet moderator temperature is set at 556 $\mathrm{K}$. Since, melting point of moderator in PWR is $615 \mathrm{~K}$ and single-phase flow is desirable for PWR and the optimum value of fuel pin pitch to radius ratio is 2.9 to 4 . For four different ratios the temperature of moderator increases from $550 \mathrm{~K}$ to $650 \mathrm{~K}$ along the vertical axis. All three except the ratio 2.3 show satisfactory result. On the other hand, moderator density reduces along the axis as temperature along the axis increases. Moderator density remains almost constant for ratio 4 and it changes rapidly for ratio 2.3. Maximum density is found almost 770 $\mathrm{kg} / \mathrm{m}^{3}$ and minimum density is $505 \mathrm{~kg} / \mathrm{m}^{3}$.

Figure 5 shows gradual decrease of coolant pressure. Several pressure drops such as: gravitational pressure drop, frictional pressure drop, acceleration pressure drop are taken into account which causes a fall of pressure along the verticle axis inside the reactor. Pressure range is found from 15.5 $\mathrm{MPa}$ to $15.65 \mathrm{MPa}$ for all four pitch to radius ratio. In PWR maximum pressure can be raised upto 15.5 $\mathrm{MPa}$ [3]. So, all the pressure range lie in optimum level.

Figure 6 shows increase of coolant velocity along the vertical axis. A significant

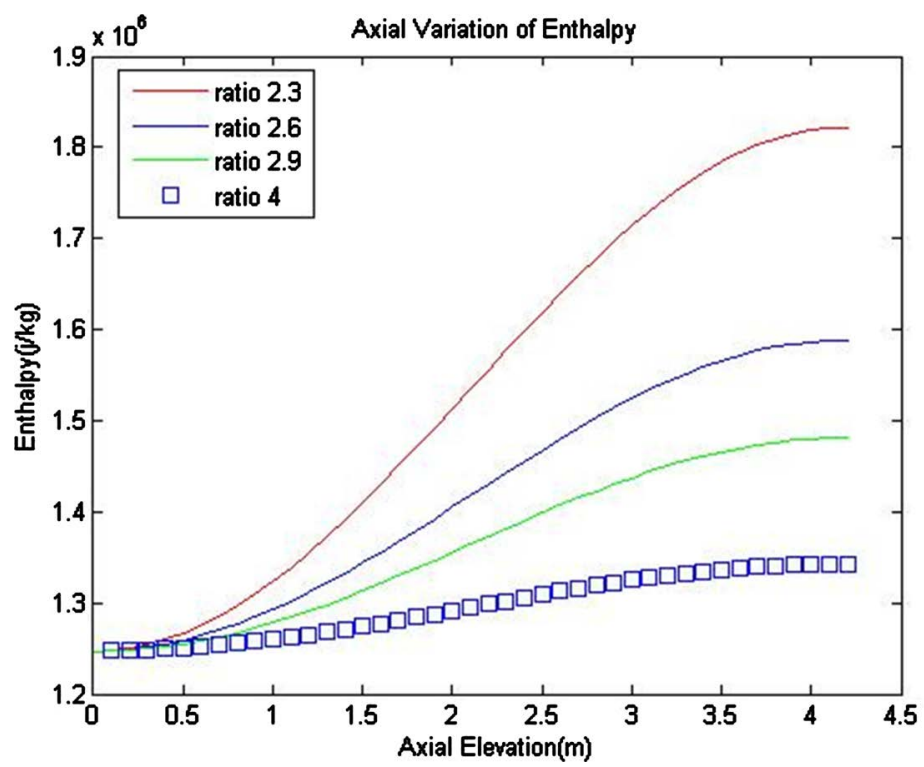

Figure 3. Enthalpy along the axial elevation. 


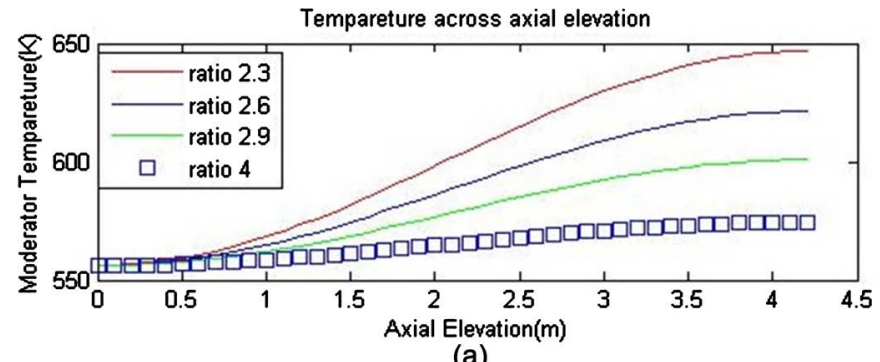

(a)

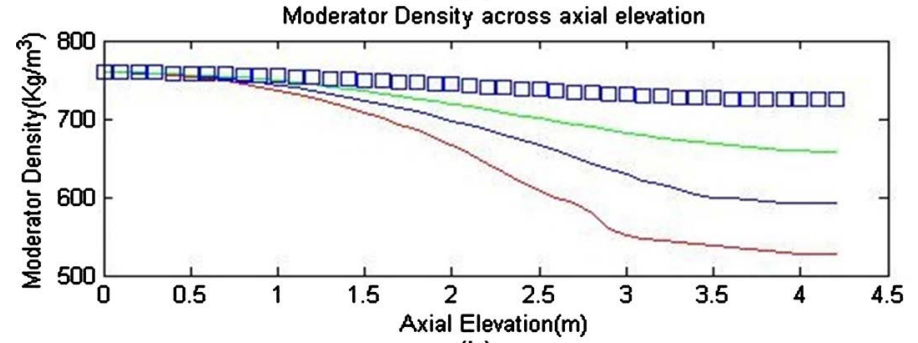

(b)

Figure 4. A variation on moderator temperature (a) and moderator density (b) along the channel.

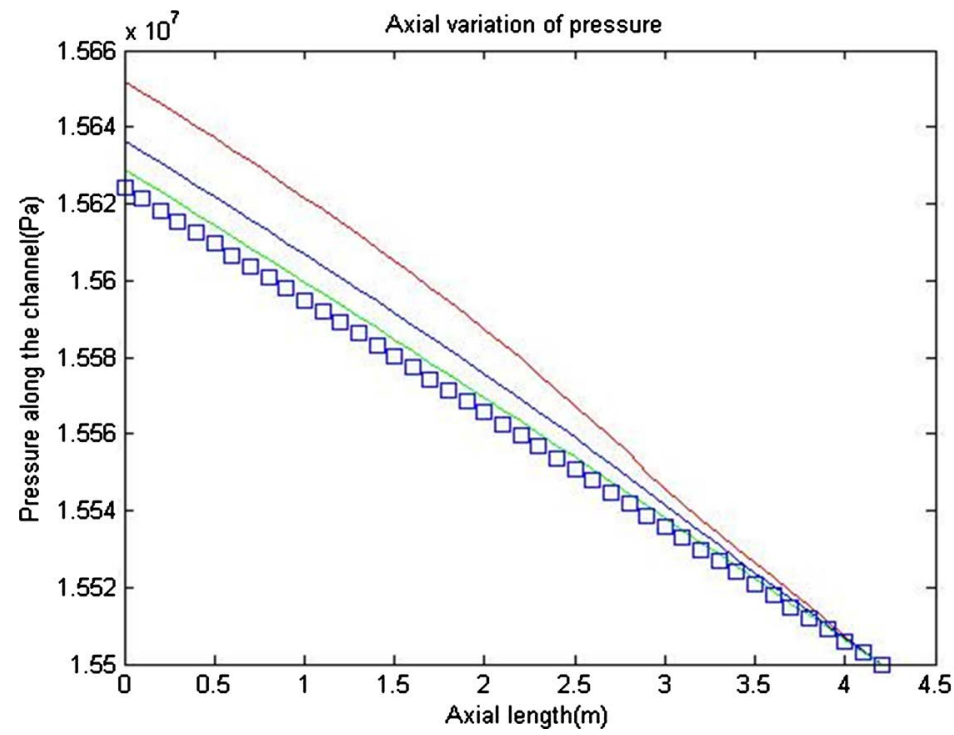

Figure 5. Axial variation of the coolant pressure.

increment has been found for 2.3 ratio. Maximum allowable coolant velocity is found $6.4 \mathrm{~ms}^{-1}$ for this ratio. The rest of the ratio shows increment from $4.4 \mathrm{~ms}^{-1}$ to $5.5 \mathrm{~ms}^{-1}$. No significant flow velocity is found for the ratio 4 .

In Figure 7, radially averaged fuel temperature is presented. As it can be seen, maximum temperature has been found for 2.3 ratio is $1580 \mathrm{~K}$. The fuel temperature is almost $50 \mathrm{~K}$ higher than the lowest value for the pin pitch to radius ratio 4. The profile seems symmetrical.

The pellet radial temperature profile at the hottest location in fuel pin is depicted in Figure 7. In the fuel pin the hottest location is found at the fuel rod position at active height of 1.5 to $2.5 \mathrm{~m}$. The thermal conductivity from $500^{\circ} \mathrm{C}$ to $2000^{\circ} \mathrm{C}$ is $4 \mathrm{~W}(\mathrm{~m} \cdot \mathrm{K})$ to $2 \mathrm{~W}(\mathrm{~m} \cdot \mathrm{K})[4]$. 


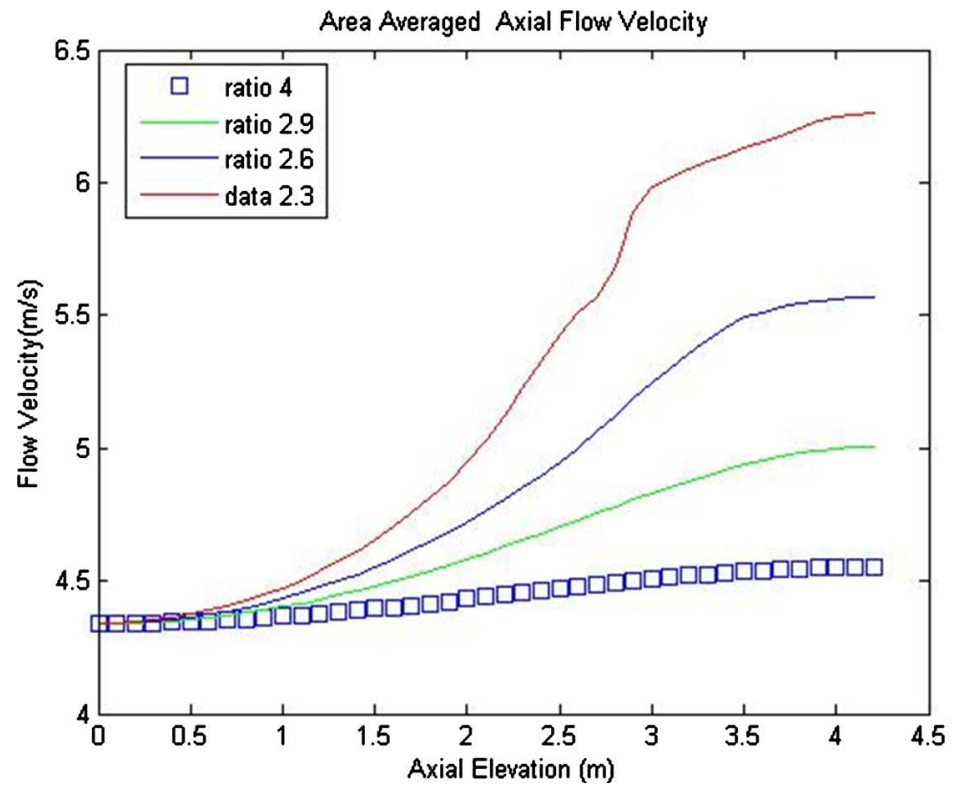

Figure 6. Coolant flow velocity along the vertical axis.

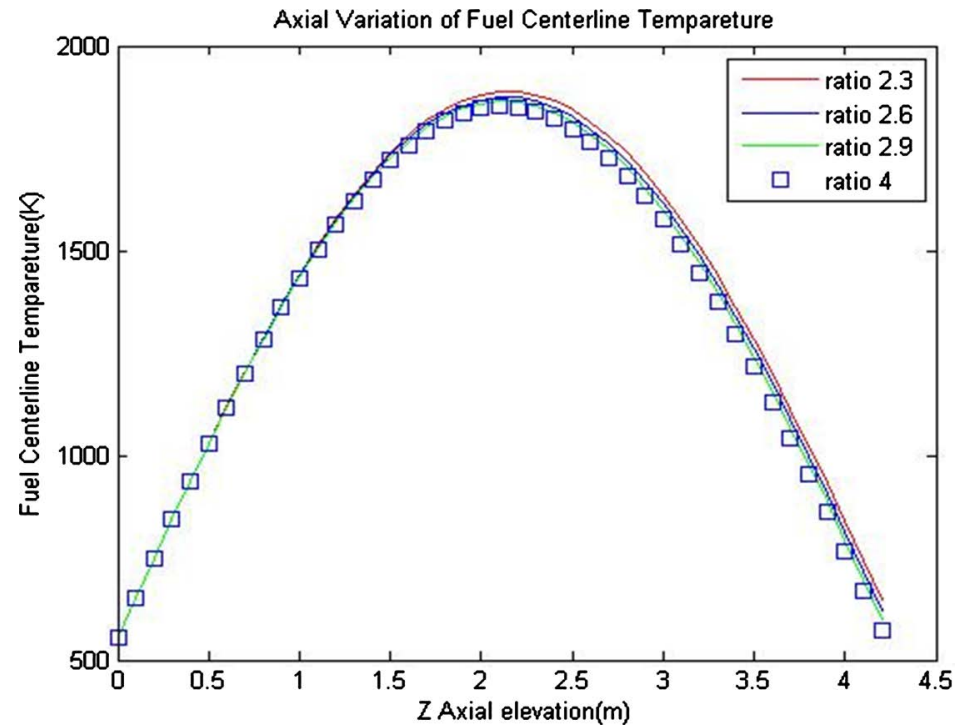

Figure 7. Fuel centerline temperature along the vertical axis.

Thermal-hydraulic behavior along the channel has been observed. This analysis has been performed on the pin cell level by varying pitch to fuel pin radius ratio. It has been found from overall all figures that ratio 2.6 is optimum and acceptable ratio. As coolant higher enthalpy results in more rise in the temperature and lowers the coolant density.

The first important constraint is that the core temperatures remain below the melting points of core components. This is particularly important for the fuel and clad materials.

There are also limits on heat transfer rate between the fuel elements and coolant, since if this heat transfer rate becomes too large, critical heat flux may be approached leading to boiling transition. This, in turn, will result in a rapid in- 
crease of the clad temperature.

In case of exceeding limit of a certain wall heat flux, there heat transfer rate will become progressively worse [5].

Critical heat flux is the primary concern for the Pressurized Water Reactors (PWR), since such reactors operate with subcooled and low quality coolants. Even for Boiling Water Reactors (BWR), which have a significantly bottom-peaked axial power profile, the DNB-risk have to be taken into account.

\section{Conclusion}

In this study, fuel pin optimization is performed for Pressurized Water Reactor. The results are specifically dependent on design specification and design criteria. The pitch to fuel pin radius ratio is better optimized from 2.6 to 2.9 which is desirable for PWR. A certain temperature limit is maintained to keep the reactor in subcooled condition. Moreover, a PWR fuel pitch and radius should be designed in such a way that will result in higher neutron economy which rises the enthalpy, and thus efficiency of the reactor. The results are obtained very preliminary. These may be used in future modelling of reactor core.

\section{Acknowledgements}

The author would like to thank Prof. Christopher Demezair from Dept of Nuclear Engineering, Chalmers University of Technology, Gothenburg, Sweden for useful discussions on the interpretation of the results.

\section{Conflicts of Interest}

The authors declare no conflicts of interest regarding the publication of this paper.

\section{References}

[1] Barrett, K. and Bragg-Sitton, S. (2012) Advanced LWR Nuclear Fuel Cladding System Development Trade-Off Study. No. INL/EXT-12-27090. Idaho National Laboratory (INL), Idaho Falls.

[2] Miki, K., Kawashima, K. and Inoue, K. (1981) Effect of Fuel Pin Pitch on Core Characteristics of Large LMFBR. Journal of Nuclear Science and Technology, 18, 71-73. https://doi.org/10.1080/18811248.1981.9733224

[3] Cooper, J.R., London, E.Ns. and Dooley, R.B. (2007) International Association for the Properties of Water and Steam.

[4] (1957) Thermal Conductivity of Uranium Dioxide. Nuclear Power.

[5] (2003) Applied Reactor Technology and Nuclear Safety. 


\section{Nomenclature}

\section{$D \quad$ diffusion coefficient}

$q^{\prime \prime} \quad$ heat dissipated to fluid from the cladding

$R_{f p} \quad$ radius of the fuel pin

$k \quad$ recoverable energy per fission event

$h$ the enthalpy

$H \quad$ the total height of the fuel pin

$R_{c o} \quad$ radius of the pin including the cladding

$z \quad$ the any parameter value along the $z$ axis or along the vertical axis

$T_{\text {mod }} \quad$ moderator temperature

$h_{1} \quad$ updated enthalpy at the end of node

$h_{0} \quad$ initial enthalpy at the beginning of node

$T_{1} \quad$ temperature at the end of node

$T_{0} \quad$ initial temperature at the beginning of the node

$T_{f p}^{\max } \quad$ is noted as maximum fuel centerline temperature

$R_{\text {eff }} \quad$ is effective thermal resistance

$q^{\prime \prime \prime} \quad$ is volumetric heat flux

\section{Greek Letters}

$\varphi \quad$ neutron flux

$v \quad$ neutron released per fission

$\Sigma_{f} \quad$ macroscopic fission cross-section

$\Sigma_{a} \quad$ macroscopic absorbing cross-section

\section{Subscripts}

$\begin{array}{ll}f p & \text { fuel pin } \\ \text { mod } & \text { moderator } \\ f & \text { fission } \\ a & \text { absorbing cross-section } \\ c o & \text { cladding } \\ \text { eff } & \text { effective }\end{array}$

